\title{
Introduction to the Journal of Evolutionary Economics special issue: the product characteristics approach to innovation studies
}

\author{
Roberto Fontana • Alessandro Nuvolari • \\ Pier Paolo Saviotti
}

Published online: 1 May 2009

(C) The Author(s) 2009. This article is published with open access at Springerlink.com

\section{Introduction}

Most goods or services people consume today in post-industrial countries are complex, heterogeneous and multi-characteristic. This has not always been the case, as the emergence of heterogeneous goods has been quite recent in historical terms. This emergence can be roughly dated to the end of the XIXth century, mainly in the USA. The presence and increasing frequency of heterogeneous goods has at least two important and related consequences: on the one hand, it affects some fundamental mechanisms of economic development and, on the other hand, it requires a number of changes in economic theory.

The emergence of new types of goods and services and their growing differentiation are not marginal epiphenomena but rather are the result of fundamental mechanisms of economic development. Two trajectories, leading respectively to (i) the growing efficiency of existing production processes and

\footnotetext{
R. Fontana

Department of Economics,University of Pavia, Via San Felice 5, Pavia, Italy

e-mail: roberto.fontana@unibocconi.it
}

R. Fontana

KITeS, Bocconi University, Via Sarfatti 25, 20136 Milan, Italy

\author{
A. Nuvolari \\ Laboratory of Economics and Management (LEM), Sant'Anna School of Advanced Studies, \\ Piazza Martiri della Liberta'33, 56127 Pisa, Italy \\ e-mail: alessandro.nuvolari@sssup.it \\ P. P. Saviotti $(\bowtie)$ \\ GREDEG, CNRS, UNSA, 250 rue Albert Einstein, 06560, Valbonne, France \\ e-mail: saviotti@inra.grenoble.fr
}


to (ii) the growing output diversity of the economic system have, for a long time, been present in economic development, although the latter acquired a considerable weight only recently. These trajectories are not independent: production efficiency had to reach a threshold supplying people with their minimum requirements of basic needs (food, housing clothing) before 'higher' goods or services could be purchased on a large scale. During the XIXth century, the above basic needs represented about $90 \%$ of working class households in the UK and the income share allocated to them only started falling at the beginning of the XXth century (Hobsbawm 1968). In fact, not only was the growing efficiency in the production of basic needs a necessary requirement for the emergence of new and more highly differentiated goods and services, but without such growing diversity the capitalist economic system was likely to run into a serious and potentially fatal bottleneck. Growing production efficiency combined with saturating demand could have led to the possibility of producing all demanded output with a declining proportion of the labor force and of other required resources (Pasinetti 1981, 1993). However, this trend could have been compensated by the emergence of new goods and services and by their growing differentiation (Pasinetti 1981, 1993; Witt 2001). Thus growing efficiency and growing diversity are complementary trends in economic development (Saviotti 1996).

As soon as new and highly differentiated goods and services appeared, economists started realizing that this emergence had important implications for economic theory. Probably the first field to receive attention was competition. The presence of highly differentiated goods and services made perfect competition implausible and gave rise to the concepts of imperfect (Robinson 1933) and of monopolistic (Chamberlin 1933) competition. Each producer could try to produce goods or services located in regions of characteristics space where no one else was present, thus acquiring a 'local' monopoly. Demand theory had to become more subtle. How could one predict the demand for a completely new or for a highly differentiated good or service? A number of economists struggled with problems such as the distinction between the quantity and quality of goods (Duesenberry 1949; Theil 19511952; Houthakker 1951-1952; Hirshleifer 1955). In the end, the economist who is credited with having made the most decisive step forward in this field is Lancaster $(1966,1971)$, although the almost simultaneous work of Ironmonger (1972) provided a very similar approach. A more detailed analysis of the evolution of these concepts can be found in Wadman (2000). The solution Lancaster proposed is that consumers do not purchase goods for their intrinsic nature, but for the services they supply, which can be represented by their characteristics. In other words, demand was not demand for goods but for the services they supplied, represented by their characteristics. The price of heterogeneous goods was not only determined by production costs but also by their characteristics. The relationship between product characteristics and their prices had been investigated since the 1930s (Court 1939) and in the 1960s it began to be used to separate product quality from inflation (Adelman and Griliches 1961; Griliches 1971). Recently, it has been realized that even the 
productivity of heterogeneous goods cannot be adequately computed without taking into account the characteristics of these products (Foster et al. 2005).

The previous paragraphs show that the potential impact of the emergence of new and highly differentiated goods and services on economic theory can be very widespread, affecting many areas of economics. While the awareness of the need for change has been high for almost a century, the actual incorporation of heterogeneous goods and services into economics has been both piecemeal and controversial. This limited incorporation of what has been a major trend in economic development reflects the tension between the need to preserve the perceived foundations of economics and the need to adjust, and possibly to replace, these foundations in order to encompass and to treat the new phenomena. A similar difficulty has been encountered in the incorporation of innovation into the main body of economics. By definition, and in particular when it is very radical, innovation gives rise to qualitative change (Saviotti 2007) and creates radical (i.e. Knightian) uncertainty, which is conceptually difficult to incorporate into a general equilibrium framework. In fact, innovation has been responsible for the introduction of new types of goods and services and for their growing differentiation.

During the industrial revolution and until the Second World War, most innovations consisted of improvements in the production of physical goods. These physical goods were created because, in the end, they would produce services useful to either producers or consumers. They all involved human knowledge about nature and supplied services to human beings. The activities of inventors and innovators consisted of identifying subsets of the external environment which, when adequately transformed, produced services useful to human beings. Product innovation lies at the interface between innovation and demand. Thus, we can in principle distinguish in any heterogeneous material good an internal structure, depending on the materials of which it is constituted and the ways in which they are combined, and the services which it supplies to its users. Correspondingly, if we are interested in both demand and supply, we can identify within each physical good two sets of characteristics, one representing the internal structure and called technical characteristics, the other representing services and called service characteristics (Saviotti and Metcalfe 1984). Henceforth, this representation will be called the 'twin characteristics approach'. The previous distinction corresponds to that introduced by Simon (1962) between the internal structure of a system and the interface with its environment. Furthermore, technical and service characteristics can be considered an analogue of the genotype and phenotype of biological organisms (Frenken 2006). This apparently technical distinction is rooted in the relationship of human beings with their external environment. Progress in human knowledge has allowed human beings to improve their adaptation to their external environment, thus improving human welfare. This subsequently led to investing greater amounts of resources in the generation of further knowledge, which in turn increased even more human welfare. As previously pointed out, this self-sustaining process could have encountered a bottleneck if the growth of human knowledge had been focused exclusively on 
the improvement of productive efficiency within a constant set of goods and services and not also on the growing differentiation of the economic system entailed by the creation of new goods and services.

Using the 'twin characteristics approach', we can represent the evolution of demand by following the development of service characteristics, which can affect directly consumer preferences, and of innovation by looking at the development of technical characteristics. In particular, we can obtain a more rigorous and operational distinction between radical and incremental innovation, with the former involving the emergence of new types of technical characteristics and the latter only involving changes in the level of characteristics. The use of the twin characteristics approach can also be very useful in providing an operational definition of dominant designs, technological paradigms and trajectories, among others. In all these cases, the use of the 'twin characteristics' approach can give us an unparalleled level of analysis and understanding of the dynamics of innovation and of technological change.

This special issue collects a selection of papers that were originally presented at the workshop on 'Demand, Product Characteristics and Innovation' organized at the Friedrich Schiller University in Jena in October 2007. The workshop was funded by the DIME (Dynamics of Innovation and Markets) Network of Excellence of the European Commission. All these papers are empirical investigations of the dynamics of innovation in particular industries, based on the 'twin characteristics' approach pioneered by Saviotti and Metcalfe (1984) exactly 25 years ago.

Corrocher and Guerzoni consider the process of price formation in the contemporary ski manufacturing industry (1992-2007). Their analysis shows the impact on price formation of different indicators of ski quality and variety in technical and service characteristics. One of the conclusions of the paper is that the relationship between technical and service characteristics and price formation must be interpreted as an outcome of different firms' strategies aimed at exploiting in different ways economies of scale and scope. In this way, the paper provides an illustration of the potential of the 'twin characteristics' approach for our understanding of patterns of competition.

Grupp and Heller examine the relationship between product quality and competition in the German market for photovoltaic cells. ${ }^{1}$ The paper combines metric rescaling technique for measuring changes in performance in multicharacteristic products with Data Envelopment Analysis (DEA). It shows that, in the case of science-based markets, quality improvement explains long term growth of the industry. However, somewhat paradoxically, in order to meet some demand segments, a reduction in performance characteristics may also

\footnotetext{
${ }^{1}$ After submitting the revised version of his paper, our colleague Hariolf Grupp passed away. His paper for this special issue is therefore one of his last contributions to the field of innovation studies. Hariolf Grupp was also one of the pioneers in the research on innovation indicators using information on technical and service characteristics (see, among others, Grupp 1998). He will be sadly missed.
} 
be required. DEA is also employed by Los and Verspagen to study environmental innovation (i.e. reduction of $\mathrm{CO}_{2}$ emissions) in passenger cars. Their results indicate that the rate of improvement in the reduction of $\mathrm{CO}_{2}$ emissions substantially differs across segments of the car market. As a consequence, it is suggested that policy makers wishing to reduce the impact of $\mathrm{CO}_{2}$ emissions should explicitly take this into account.

The case of environmental policies for improving sustainability of the car as transport system is also examined by Schwoon, Alkemade, Frenken and Hekkert. This paper shows the way in which technical characteristics can be used to provide a detailed map of the space of technological opportunities, which is akin to the idea of the fitness landscape in biology. This reconstructed technological landscape is then used to assess the merits and limitations of alternative transition paths towards environmental-friendly technological solutions. As with the previous paper, this contribution also highlights one of the advantages of a quantitative approach based on characteristics, and is able to provide specific policy implications, whereas most of the literature tends to remain rather generic or vague. Castaldi, Fontana and Nuvolari apply the 'twin characteristic approach' to study the evolution of tank technology over the period 1915-1945. Using principal component analysis, they provide a detailed assessment of the mains trends of development of tanks understood as technological systems. One of their findings is that the technological superiority of German and Russian tanks during World War II was more in the 'eye of the beholder' rather than an actual technological gap, a result that sheds a different light on the military doctrine concerning the use of tanks prevailing in Germany and Soviet Russia in comparison to those of the Allies. Indeed, one of the aims of the paper is to show the potential of the approach for the field of history of technology. Historians of technology tend mainly to focus on documental evidence and, usually, and to eschew the use of quantitative techniques of analysis. This paper suggests instead that detailed analysis of the trend of evolution of the characteristics of a product population can generate useful insights and provide a different perspective in the analysis of the documental evidence.

Another empirical application of the 'twin characteristics' approach, based on the use of principal component analysis, is contained in the paper by Windrum, Diaz and Filiou. They examine the dynamics of innovation in mobile phone handsets. Their findings point to the existence of a complex and non-linear pattern of imaging between product and service characteristics, as originally posited by Saviotti and Metcalfe (1984). Moreover, there seems to be a restricted number of core technical characteristics, which seems to be responsible for the performance levels achieved in the most relevant service characteristics. It is on these core technical characteristics that the competition between manufacturers seems to focus. Finally, the paper by Coad focuses on the relationship between the distribution in the technical characteristics of products and the distribution of their prices. Relying on hedonic price analysis, one of the earliest approaches combining information on product prices and characteristics, it shows that price distributions in different markets 
seem to reveal the existence of complicated patterns of interactions among the characteristics affecting the overall quality of a product.

Altogether, the papers contained in this special issue provide a good illustration of the variety of approaches that can be employed in detailed studies of product characteristics. They also provide a good overview of the riches of insights that can be gained using this approach. As the availability of datasets and information on product prices and technical characteristics is likely to increase in the near future, empirical studies based on product characteristics seem to represent a research trajectory that is worthwhile pursuing, especially by younger generations of researchers. ${ }^{2}$

Open Access This article is distributed under the terms of the Creative Commons Attribution Noncommercial License which permits any noncommercial use, distribution, and reproduction in any medium, provided the original author(s) and source are credited.

\section{References}

Adelman I, Griliches Z (1961) On an index of quality change. J Am Stat Assoc 56:535-48

Chamberlin EJ (1933) The theory of monopolistic competition. Harvard University Press, Cambridge

Court AT (1939) Hedonic price indexes with automotive examples, in the dynamics of automobile demand. General Motors Corporation, New York

Duesenberry JS (1949) Income, saving and the theory of consumer behaviour. Harvard University Press, Cambridge

Foster L, Haltiwanger J, Syverson C (2005) Reallocation, firm turnover, and effiiency: selection on productivity or profitability? NBER working paper series. Working paper 11555. http://www.nber.org/papers/w11555

Frenken K (2006) Innovation, evolution and complexity theory. Edward Elgar, Cheltenham

Griliches Z (ed) (1971) Price indexes and quality change. Harvard University Press, Cambridge

Grupp H (1998) Foundations of the economics of innovation: theory, measurement and practice. Edward Elgar, Cheltenham

Hirshleifer J (1955) The exchange between quantity and quality. Q J Econ 69:596-606

Hobsbawm EJ (1968) Industry and empire. Penguin, Harmondsworth

Houthakker H (1951-1952) Compensated changes in the quantities and qualities consumed. Rev Econ Stud 19(50):155-164

Ironmonger DS (1972) New commodities and consumer behavior. Harvard University Press, Cambridge

Lancaster KJ (1966) A new approach to consumer theory. J Polit Econ 14:133-156

Lancaster KJ (1971) Consumer demand: a new approach. Columbia University Press, New York

Pasinetti LL (1981) Structural change and economic growth. Cambridge University Press, Cambridge

Pasinetti LL (1993) Structural economic dynamics. Cambridge University Press, Cambridge

Robinson J (1933) The theory of imperfect competition. Macmillan, London

Saviotti PP (1996) Technological evolution, variety and the economy. Edward Elgar, Cheltenham Saviotti PP (2007) Qualitative change and economic development. In: Hanusch H, Pyka A (eds) Elgar companion to neo-schumpeterian economics. Edward Elgar, Cheltenham

\footnotetext{
${ }^{2}$ Within the DIME Network of Excellence, the construction an open platform to share information on product characteristics data-sets is currently being implemented. Some of the datasets, used in this special issue, will be made available on this platform.
} 
Saviotti PP, Metcalfe JS (1984) A theoretical approach to the construction of technological output indicators. Res Policy 13:141-151

Simon HA (1962) The architecture of complexity. Proc Am Philos Soc 106:467-482 (reprinted in: Simon HA (1981) The sciences of the artificial. MIT, Cambridge)

Theil H (1951-1952) Quality, prices and budget enquiries. Rev Econ Stud 19(3):129-147

Wadman WM (2000) Variable quality in consumer theory. M.E. Sharp, New York

Witt U (2001) Learning to consume: a theory of wants and the growth of demand. J Evol Econ $11: 23-26$ 